\title{
The benzene metabolite hydroquinone enhances G2-chromosomal radiosensitivity by inducing a less-efficient G2-M-checkpoint in irradiated lymphocytes
}

\author{
VASILIKI I. HATZI ${ }^{1}$, GEORGIA I. TERZOUDI ${ }^{1}$, GABRIEL E. PANTELIAS ${ }^{1}$, \\ CHARA SPILIOPOULOU $^{2}$ and VASILIOS MAKROPOULOS ${ }^{3}$
}

\begin{abstract}
${ }^{1}$ Institute of Nuclear Technology and Radiation Protection, National Center for Scientific Research, NCSR 'Demokritos', Athens; ${ }^{2}$ Department of Forensic Medicine and Toxicology, Medical School, University of Athens, Athens;

${ }^{3}$ Hellenic Institute for Occupational Health and Safety, ELINYAE, Athens, Greece
\end{abstract}

Received December 18, 2006; Accepted January 29, 2007

\begin{abstract}
The hypothesis tested is that a 24-h pre-irradiationexposure of peripheral blood lymphocytes (PBL) to the benzene metabolite hydroquinone (HQ), at doses that are nonacutely toxic $(5 \mu \mathrm{M})$, induces a less efficient G2-M-checkpoint and enhances the G2-chromosomal radiosensitivity in a statistically significant manner $(\mathrm{p}<0.01)$. A less efficient $\mathrm{G} 2-\mathrm{M}$ checkpoint may allow the transition of damaged cells from G2- to M-phase and experimental data in the present work support this hypothesis. In fact HQ sensitizes lymphocytes obtained from healthy donors, as they exhibit increased G2-chromosomal radiosensitivity which interestingly is similar to that observed in cases of radiosensitive cancer-prone individuals. This finding is important since a deficiency in cell cycle checkpoints and an increase in G2-chromosomal radiosensitivity are linked to chromosomal instability, cancer proneness and the development of leukemia. The observed chromosome radiosensitization may be a consequence either of an effect of HQ on the initial induction of radiation-induced chromosomal aberrations, or on the DNA repair capacity of the cells, or it may be linked to HQ-induced alterations in the cell cycle and feedback control mechanism during the G2- to M-phase transition. In order to elucidate which is the mechanism involved, conventional cytogenetics and premature chromosome condensation (PCC) methodologies were applied. The experimental data obtained support the hypothesis that HQ increases G2-chromosomal radiosensitivity in human peripheral blood lymphocytes by inducing a less efficient G2-M-checkpoint, facilitating thus the transition of damaged cells from G2- to M-phase.
\end{abstract}

Correspondence to: Dr Georgia I. Terzoudi, Institute of Nuclear Technology and Radiation Protection, National Centre for Scientific Research, NCSR 'Demokritos', Athens, Greece

E-mail: georgia@ipta.demokritos.gr

Key words: hydroquinone, G2-checkpoint, PCC, G2-chromosomal radiosensitivity

\section{Introduction}

It has long been known from both epidemiologic studies and laboratory models that benzene is hemotoxic and leukemogenic (1-3). However, the precise mechanism by which benzene and its phenolic- and quinone-based metabolites induce leukemias is not fully characterized. Benzene is not a classic chemical carcinogen as there is little evidence for the production of highly electrophilic DNA-binding metabolites in vivo (4). It is mainly metabolized in the liver and bone marrow and it is believed that the induced hematopoietic cancers in humans are mediated through the generation of reactive oxygen species by its principal metabolite, hydroquinone (HQ) (2). Human exposure to HQ occurs through plant consumption (e.g., wheat germ, tea from berry leaves, coffee), beverages, cigarette smoke, cosmetics (e.g., skin lighteners, hair dyes) and medical products (e.g., treatment of melasma and freckles) $(3,5,6)$. Furthermore, exposure to HQ may occur via the occupational environment. In particular, HQ is widely used as a reagent in black and white photographic developer solutions. As a result, $\mathrm{X}$-ray technicians, photographic developer solution makers and amateur photographers, who develop their own black-andwhite films, can be exposed to HQ dermally or by inhalation. Other occupational groups in which HQ exposure may occur are: antioxidant makers, hairdressers (7) and cosmetologists, paint makers, organic chemical synthesizers, plastic stabilizer workers and rubber coating workers (8). It has been hypothesized that HQ derived form dietary ingestion plays crucial role in producing some forms of de novo leukemia in the general population (9).

Although it is not possible to draw firm conclusions concerning the carcinogenic potential of HQ, some positive results open new questions concerning the carcinogenic profile of the chemical. It has been reported that HQ causes gene mutations (10) and DNA damage (11), inhibits topoisomerase II and, possibly, alters hematopoiesis and clonal selection $(12,13)$. However, neither benzene nor the majority of its metabolites are mutagenic in the Ames test (14) and recent studies on the mechanisms underlying HQ-induced leukaemia focus on the non-random distribution of chromosome breaks and nonrandom aneuploidy induced mainly by epigenetic effects and 
the selective loss of chromosomes that are related to leukemogenesis (15). Benzene and its metabolites as well as ionising radiation (IR) are known to be associated with acute myeloid leukaemia (AML) $(1,3)$ and a recent case report study referring to occupational exposure to HQ may support such a possibility (13). Increased risk of AML and cancer predisposition in general is linked with certain inherited conditions such as Ataxia Telangiectasia and Nijmegen breakage syndrome $(16,17)$. Interestingly, these conditions are also associated with excessive chromosomal fragility, which appears either spontaneously or following G2-phase irradiation of peripheral blood lymphocytes (PBL). The latter, can be analyzed at the subsequent metaphase using the so called G2-chromosomal radiosensitivity assay (G2-assay) (18-20). Moreover, using the G2-assay, twenty other inherited cancer-prone conditions have been shown to exhibit some degree of elevated chromosomal radiosensitivity (19) and this characteristic has been proposed as a biological indicator for cancer proneness $(18,21,22)$.

In the present study, we report that the benzene metabolite $\mathrm{HQ}$, at doses that are not acutely toxic to PBL, induces a less efficient G2-M-checkpoint following irradiation and enhances G2-chromosomal radiosensitivity, which is quantitated as excessive chromosomal fragility in the subsequent metaphase. This observation is interesting since a deficiency in cell cycle checkpoints is linked to both cancer proneness and the increase in G2-chromosomal radiosensitivity (23-25). This increase is of the same order magnitude as that observed in cases of radiosensitive cancer-prone individuals and, therefore, may cause chromosomal instability and the development of AML. Excessive chromosomal fragility may be a consequence either of an effect of HQ on the initial induction of radiation-induced chromosomal aberrations, or on the DNA repair capacity of the cells in the presence of HQ or it may also be linked to HQ-induced alterations in the cell cycle and feedback control mechanism during the G2- to M-phase transition. To elucidate the mechanisms involved, we have used conventional cytogenetics and premature chromosome condensation (PCC) methodologies, and the experimental data obtained support the hypothesis that HQ increases G2-chromosomal radiosensitivity by inducing a less-efficient G2-M-checkpoint in irradiated lymphocytes, allowing thus the progression of unrepaired damaged cells from G2- to M-phase.

\section{Materials and methods}

Cell culture, irradiation conditions and chemicals. Peripheral blood samples were taken by venipuncture from healthy individuals and collected in heparinized tubes. Whole blood $(0.5 \mathrm{ml})$ was added to each culture tube containing $5 \mathrm{ml}$ of McCoy's 5A medium, supplemented with $10 \%$ foetal calf serum (FCS), $1 \%$ L-glutamin, $1 \%$ antibiotics [penicillin (100 U/ $\mathrm{ml})$ - streptomycin $(100 \mu \mathrm{g} / \mathrm{ml})], 2 \%$ phytohemagglutinin. All incubations were at $37^{\circ} \mathrm{C}$ for $72 \mathrm{~h}$ in a humidified incubator (5\% $\mathrm{CO}_{2}, 95 \%$ air). Human lymphocytes were obtained from freshly drawn blood, separated by Ficoll-Paque sedimentation and suspended in McCoys's 5A medium supplemented with $10 \%$ FCS. Isolated lymphocytes were used at their G0-phase and irradiated at various doses (1-6 Gy). Chinese hamster ovary $(\mathrm{CHO})$ cells were grown in McCoy's $5 \mathrm{~A}$ culture medium supplemented with $10 \%$ FCS and antibiotics. PCC experiments described here were performed using M-phase hamster cells obtained from exponentially growing cells after a 4-h treatment with $0.2 \mu \mathrm{g} / \mathrm{ml}$ colcemid. All culture media were obtained from Biochrom-AG unless stated otherwise. HQ was prepared in PBS and added $48 \mathrm{~h}$ or $71 \mathrm{~h}$ after culture initiation at a final concentration of $5 \mu \mathrm{M}$. Calyculin-A (Wako) was prepared as a 1-mmol/l solution in ethanol. 5-Bromodeoxyuridine (BrdU) was added at a final concentration of $20 \mu \mathrm{M}$. All chemicals were from Sigma-Aldrich unless stated otherwise. Irradiations were carried out at room temperature with a GammaCell 220 irradiator (Atomic Energy of Canada Ltd., Ottawa, Canada) and at a dose rate of $1 \mathrm{~Gy} / \mathrm{min}$. For each experimental point standard deviations of the mean values from three independent experiments were calculated. Data were evaluated statistically by Student's t-test. All p-values were considered statistically significant at $\mathrm{p}<0.05$.

Cell harvesting. Two hours before the total incubation period of $72 \mathrm{~h}$, cells were arrested in the metaphase stage of their mitosis by the addition of colcemid (final concentration in the medium $0.1 \mu \mathrm{g} / \mathrm{ml}$ ) (Biochrom AG). The cultured cells were harvested by speed centrifugation $(1450 \mathrm{rpm})$ and treated with hypotonic $\mathrm{KCl}(0.075 \mathrm{M})$ (Sigma-Aldrich), fixed with freshly prepared 3:1 methanol-acetic acid (v/v) (purchased from Fluka and Baker respectively) and $20 \mu \mathrm{l}$ of cell suspension was dropped on wet slides. The slides were air-dried and stained in a $2 \%$ solution of Giemsa dye (Merck) for $15 \mathrm{~min}$ and rinsed with water. Air-dried slides were embedded with cover slips and coded for analysis. From each culture, 2000 nuclei were examined to determine the mitotic index (MI, percentage of cells undergoing mitosis). From each treatment group, 50 well-spread metaphases were analyzed by microscopic examination.

Sister chromatid exchange (SCE). BrdU, was added $24 \mathrm{~h}$ after culture initiation. Cultures were incubated at $37^{\circ} \mathrm{C}$ for $72 \mathrm{~h}$ prior to cell harvest. During this culture period, incorporation of BrdU into replicating cells allows for the unequivocal identification of second division metaphase cells. The cultured cells were harvested as described before. Air-dried slides were stained in the dark using Fluorescence-Plus-Giemsa (FPG) technique (26) and the SCE analysis was carried out in metaphase as well as in G2-phase cells using a new cytogenetic approach (27). For SCE scoring, the criteria suggested by Carrano and Natarajan (28) were applied.

G2-assay. In order to test the effect of HQ on G2-chromosomal radiosensitivity, exponentially growing cells from PBL cultures were irradiated with $1 \mathrm{~Gy}$ in the presence of subgenotoxic doses $(5 \mu \mathrm{M})$ of HQ. The cell cultures were then incubated for $30 \mathrm{~min}$ at $37^{\circ} \mathrm{C}$ and subsequently treated with $0.2 \mu \mathrm{g} / \mathrm{ml}$ colcemid for $1 \mathrm{~h}$ to arrest cells at metaphase using a modified G2-assay protocol (20). Cells were fixed and coded for analysis to avoid bias. Chromosomal breaks were visualized and quantified as chromatid breaks in the subsequent metaphase. For each experimental point, approximately 50 cells at metaphase were analyzed for radiation-induced chromatid damage. Only chromatid breaks being defined as misaligned discontinuities and gaps longer than a chromatid width were considered for scoring. 
Premature chromosome condensation using PEG-mediated cell fusion. Mitotic $\mathrm{CHO}$ cells and isolated lymphocytes were washed separately with McCoy's 5A medium without serum and mixed in a ratio 1:5 in a 15 round bottom culture tube. After centrifugation at $200 \mathrm{x}$ g for $5 \mathrm{~min}$, the supernatant was discarded without disturbing the cell pellet and $0.2 \mathrm{ml}$ of $50 \%$ (w/v) PEG 1500 (Roche) was added and held for $1 \mathrm{~min}$. Subsequently $2 \mathrm{ml}$ of PBS was slowly added, the tube was gently shaken and the cell suspension was centrifuged at $200 \mathrm{x} \mathrm{g}$ for $5 \mathrm{~min}$. The supernatant was discarded and the pellet resuspended in $0.7 \mathrm{ml}$ of McCoy's 5A growth medium supplemented with colcemid (final concentration in the medium $0.1 \mu \mathrm{g} / \mathrm{ml}$ ) (Biochrom AG). After $75 \mathrm{~min}$ at $37^{\circ} \mathrm{C}$, cell fusion and PCC induction was completed and chromosome preparations were obtained by standard cytogenetic procedures (29). For each experimental point, 50 lymphocytes in G0-phase were scored for excess chromatid breaks.

Premature chromosome condensation using chemical induction. To test whether the increased chromosomal damage after exposure to IR and HQ is linked to cell cycle and feedback control mechanism during the G2- to M-phase transition (G2-checkpoint), we used the PCC methodology by means of calyculin-A (50 nM) $(24,27,30)$. Approximately 1000 cells per each experimental point were analysed and the effect of HQ when combined with IR on G2- to M-phase transition was determined using the following formula: [no. of cells in G2-phase / (no. of cells in G2-phase + no. of cells in Mphase)] x $100 \%$.

\section{Results}

In the present study, the hypothesis tested is that exposure of PBL to the benzene metabolite HQ, at doses that are nonacutely toxic, enhances the G2-chromosomal radiosensitivity by affecting the transition of damaged cells from G2- to Mphase. For this purpose, $5 \mu \mathrm{M}$ HQ were used and their effect on the induction and repair of radiation-induced chromosomal damage, as well as on the activation of G2-checkpoint, were thoroughly studied. The concentration of $5 \mu \mathrm{M}$ HQ was characterized as non-acutely toxic, since a 24-h exposure of non-irradiated PBL cultures did not induce a statistically significant increase in the number of CAs and SCEs scored at metaphase or G2-phase, when compared to that observed in non-treated cells.

In order to test the effect of HQ on chromosomal radiosensitivity, PBL cultures from six different healthy donors were treated with $5 \mu \mathrm{M}$ HQ for $1 \mathrm{~h}$ or $24 \mathrm{~h}$ before their exposure to $1 \mathrm{~Gy}$ of $\gamma$-rays in G2-phase. The cell cultures were incubated at $37^{\circ} \mathrm{C}$ for $30 \mathrm{~min}$ and colcemid was added for $1 \mathrm{~h}$ in order to arrest the G2-irradiated cells at metaphase. A statistically significant increase was observed (t-test, $\mathrm{t}=4.49$, $0.001<\mathrm{p}<0.01)$ in all samples exposed to both IR and $5 \mu \mathrm{M}$ HQ (24 h treatment), when compared to the samples exposed to IR only. Treatment with HQ for $1 \mathrm{~h}$ only before irradiation did not show any increase in radiation-induced chromosomal damage compared with the samples exposed to IR only (Fig. 1).

Four different sets of experiments were carried out in order to investigate whether the mechanism by which HQ increases

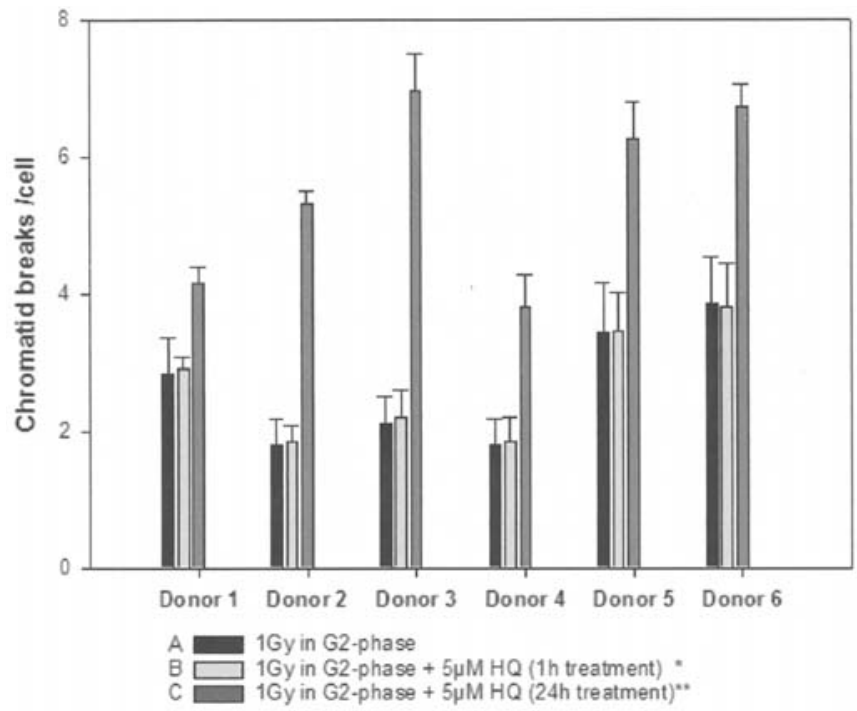

Figure 1. Chromatid breaks per cell for six different healthy donors after $1 \mathrm{~Gy}$ G2-phase $\gamma$-radiation of $72 \mathrm{~h}$ PBL cultures (G2-assay) as well as the combined effect after a 1-h or 24-h pre-irradiation exposure to non-acutely toxic dose of HQ $(5 \mu \mathrm{M})$. The dose of $5 \mu \mathrm{M}$ of HQ was characterized as non-acutely toxic since it did not induce any chromosomal damage or increase in SCEs in nonirradiated cultures. Standard deviations of the mean values from 3 experiments were calculated for each experimental point. Data were evaluated statistically by Student's t-test. All p-values were considered statistically significant at $\mathrm{p}<0.05$. *Significance of the difference in sample means between A and B: $\mathrm{t}$-test, $(\mathrm{t}=0.03), \mathrm{p}>0.5 .{ }^{* *}$ Significance of the difference in sample means between $\mathrm{A}$ and $\mathrm{C}$ : $\mathrm{t}$-test, $(\mathrm{t}=4.49), 0.001<\mathrm{p}<0.01$.

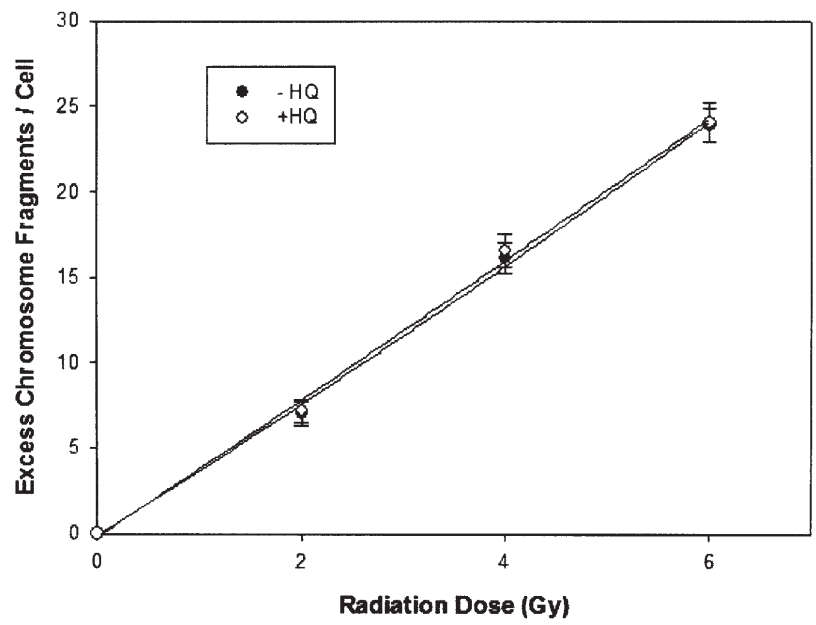

Figure 2. Excess chromosome fragments per cell as a function of radiation dose in G0 lymphocytes scored immediately after irradiation in interphase by means of the PCC method, in the presence or absence of a 24-h pre-irradiation treatment with $5 \mu \mathrm{M}$ HQ. The presence of HQ did not affect the yield of radiation-induced initial chromosomal damage. Bars indicate standard deviations calculated from the mean values of three independent experiments.

chromosomal radiosensitivity and induces excessive fragility is the result of its effect on either the initial DNA damage induced by radiation, or on the DNA repair capacity of the cells, or on the cell cycle and feedback control mechanisms during the G2- to M-phase transition.

The effect of HQ on the initial induction of radiationinduced chromosome aberrations in G0 lymphocytes, isolated from peripheral blood, was investigated in the first set of 


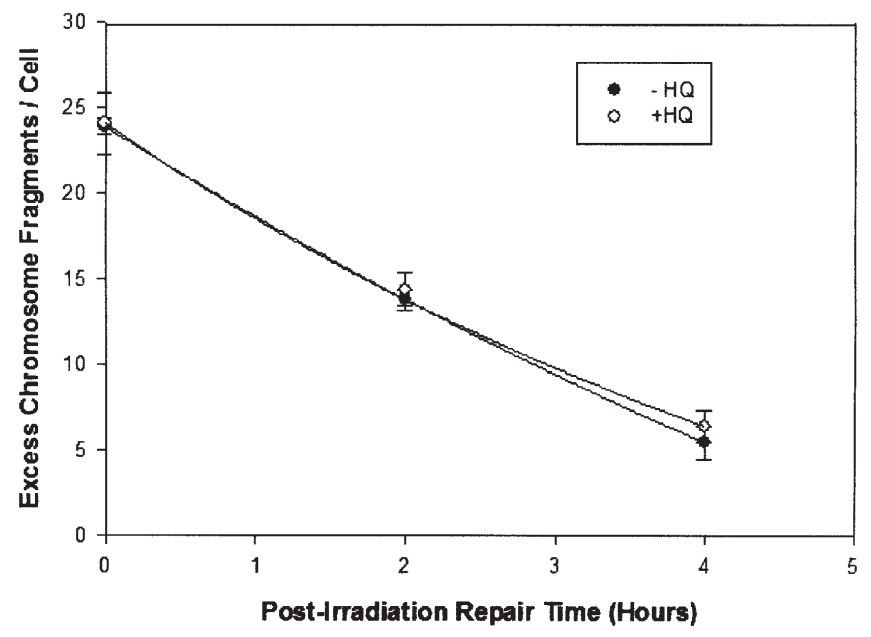

Figure 3. Yield of excess chromosome fragments per cell vs. post-irradiation time for human peripheral blood lymphocyte cultures exposed to $6 \mathrm{~Gy}$ $\gamma$-radiation and analysed in interphase using cell fusion and PCC induction, in the presence or absence of a 24 -h pre-irradiation treatment with $5 \mu \mathrm{M} \mathrm{HQ}$. The presence of HQ did not affect the repair kinetics of radiation-induced chromosomal damage. Standard deviations of mean values from three independent experiments were calculated for each experimental point.

experiments. For this purpose, G0 lymphocytes were irradiated at doses of 2, 4 and 6 Gy. The chromosomal damage in the lymphocytes was evaluated immediately after irradiation in the presence or absence of HQ ( $5 \mu \mathrm{M}$, for the last $24 \mathrm{~h})$, using cell fusion with mitotic CHO cells and PCC induction (29). Linear dose response curves were obtained and the yields of PCC fragments per cell per Gy in the presence or absence of HQ in the lymphocyte culture were found to be similar (Fig. 2).

The second set of experiments was designed to study the effect of HQ on the repair kinetics of G0 lymphocytes that were exposed to $5 \mu \mathrm{M}$ HQ for $24 \mathrm{~h}$ and subsequently irradiated with a dose of $6 \mathrm{~Gy}$. The effect of this subgenotoxic dose of HQ on the repair of radiation-induced chromosomal damage was evaluated at various time intervals $(0,2$, and $4 \mathrm{~h})$ after irradiation exposure, using cell fusion and the PCC methodology. The results obtained from three independent experiments showed that equal yields in the number of PCC breaks per cell were obtained in the presence or absence of HQ (Fig. 3).

The effect of HQ in the activation of the G2-checkpoint, following exposure to IR, was evaluated in the third set of experiments using conventional cytogenetics to estimate the percentage of cells in metaphase (mitotic index) (Fig. 4A). A statistically significant increase $\left[\mathrm{t}_{(\mathrm{a})}=5.79,0.001<\mathrm{p}<0.01\right.$ and $\left.\mathrm{t}_{(\mathrm{b})}=4.47,0.01<\mathrm{p}<0.02\right]$ in MI of cells exposed both to HQ $(5 \mu \mathrm{M}, 24 \mathrm{~h})$ and IR (1 Gy) was noticed when compared to those exposed to IR only. Specifically, Fig. 4A shows a 9-fold increase in MI in cells exposed to HQ and IR, when compared to those exposed to IR only.

The effect of HQ on the G2-checkpoint was further tested using a fourth set of experiments designed to study uniquely the cell cycle progression after exposure both to HQ and IR. For this purpose, we applied a novel protocol using calyculin-A in order to visualize, quantitate and classify the exact progression stage of the interphase cells (e.g., early, middle, late) of the G1-, S-, and G2-phases of the cell cycle and also
A

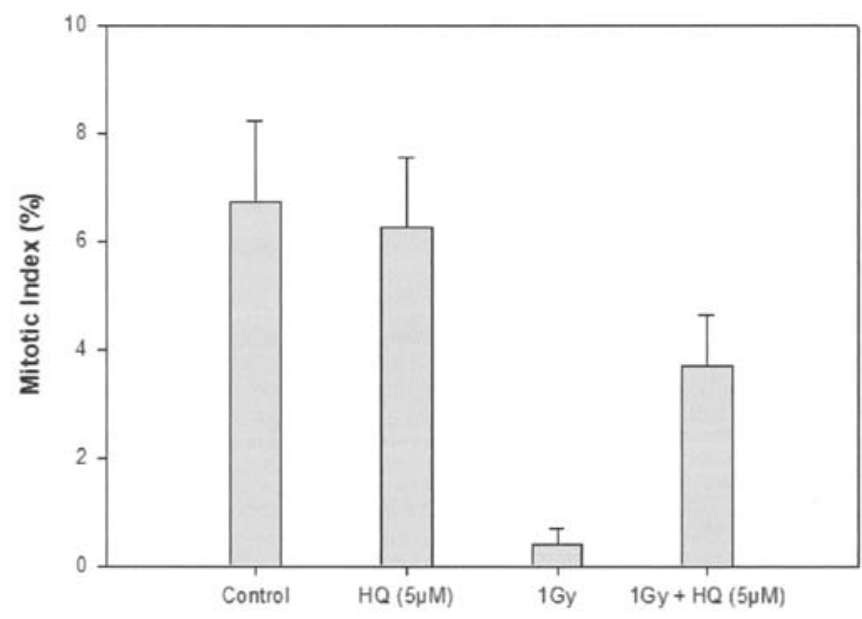

B

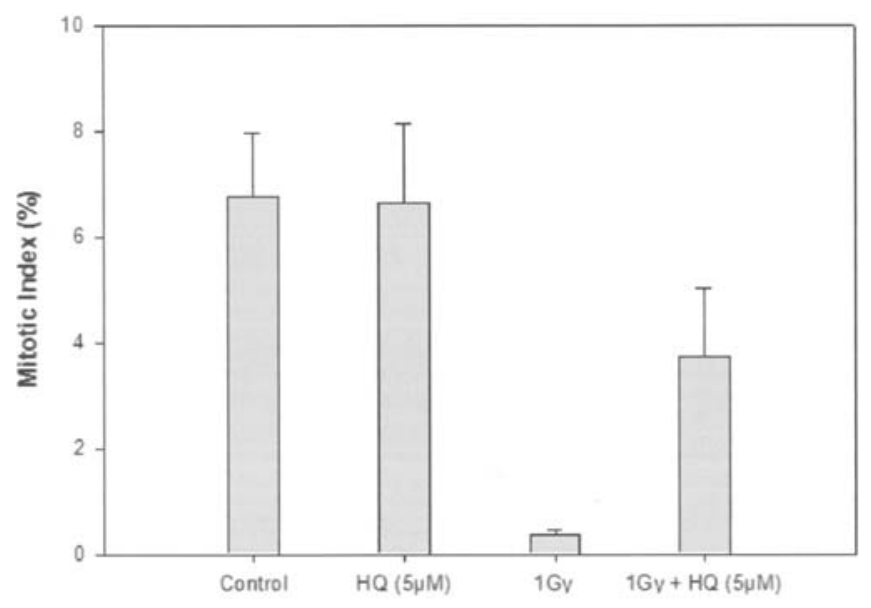

Figure 4. Mitotic indices after exposure to $5 \mu \mathrm{M}$ of HQ, 1 Gy $\gamma$-radiation as well as to both agents estimated using (A) conventional cytogenetics or (B) calyculin-A induced PCC. Hydroquinone exposure induced a statistically significant increase in the mitotic index (MI) in the irradiated cells. Similar mitotic indices were obtained using the two different methodologies. Standard deviations of the mean values from three experiments were calculated for each experimental point. Data were evaluated statistically by Student's t-test. (A) Significance of the difference in sample means between $1 \mathrm{~Gy}$ and [1 Gy + HQ $(5 \mu \mathrm{M})$ ]: $\mathrm{t}$-test, $(\mathrm{t}=5.79), 0.001<\mathrm{p}<0.01$. (B) Significance of the difference in sample means between $1 \mathrm{~Gy}$ and $[1 \mathrm{~Gy}+\mathrm{HQ}(5 \mu \mathrm{M})]$ : t-test, $(\mathrm{t}=4.47)$, $0.01<\mathrm{p}<0.02$.

to differentiate G2-phase cells from M-phase cells (24). As this methodology enables as well the estimation of MI values, a 10-fold increase was found in MI in cells exposed both to HQ and IR compared to those exposed to HQ only (Fig. 4B). Furthermore, 1000 cells from PBL cultures that were exposed to either $5 \mu \mathrm{M} \mathrm{HQ}$, or to $1 \mathrm{~Gy} \gamma$-irradiation, in the G2-phase, or to both factors, were classified according to their cell cycle phase (G1, S, G2 and M) (Fig. 5). The ratio G2/G2+M was also estimated. It is worth noticing that after exposure to HQ combined with $\mathrm{G} 2$-phase IR, a statistically significant ( $\mathrm{t}=8.33$, $0.001<\mathrm{p}<0.01$ ) lower ratio of $\mathrm{G} 2 / \mathrm{G} 2+\mathrm{M}$ was observed with respect to cells exposed to IR only (Fig. 6).

\section{Discussion}

In this study, we have tested the hypothesis that the benzene metabolite $\mathrm{HQ}$, at doses that are not acutely toxic to PBL, 


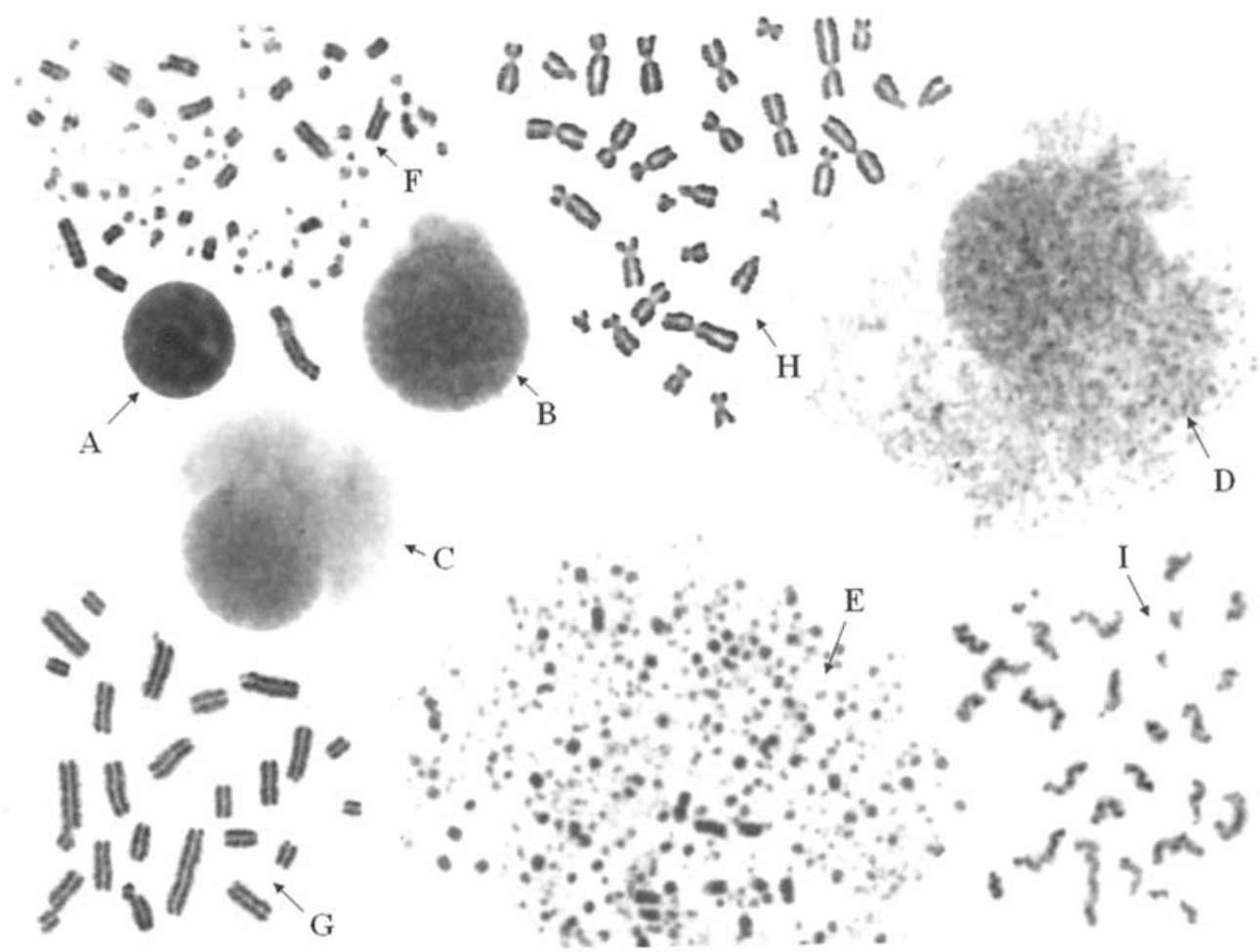

Figure 5. Calyculin-A-induced premature chromosome condensation (PCC) enables classification of cultured lymphocytes in the different phases of the cell cycle: G0 (A), middle-G1 (B), late-G1 (C), early-S (D), middle-S (E), late-S (F), G2 (G), metaphase (H), late telophase postmitotic G1 (I). Note that PCC induction depends on the cell cycle stage, the G2-phase cell is distinguishable from the M-phase cell. Not all chromosomes are included in the figure.

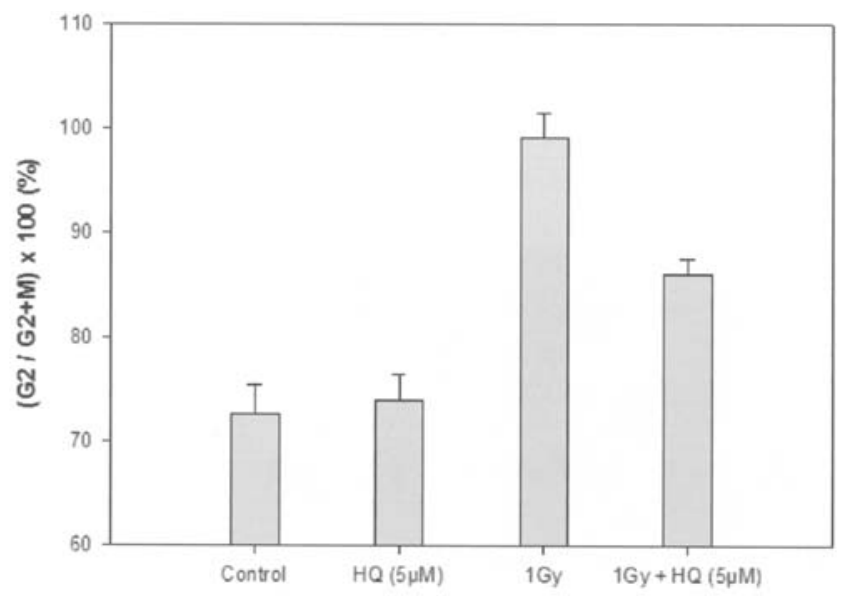

Figure 6. Effect of $5 \mu \mathrm{M}$ HQ on cell cycle progression and transition into M-phase of $\gamma$-irradiated lymphocytes using calyculin-A induced PCC. One thousand cells from each sample were analyzed according to their chromatin morphology and classified as G1, S, G2 and M. Using calyculin-A, the morphology of M-phase differs from that of G2-phase cells since the latter lack visible constriction at their centromeric regions (Fig. 5), enabling thus the calculation of $\mathrm{G} 2 / \mathrm{G} 2+\mathrm{M}$ ratio. The presence of $\mathrm{HQ}$ partially abrogates the G2-checkpoint and releases cells from the G2-block. Standard deviations of the mean values from three experiments were calculated for each experimental point. Significance of the difference in sample means between $1 \mathrm{~Gy}$ and $[1 \mathrm{~Gy}+\mathrm{HQ}(5 \mu \mathrm{M})]$ : $\mathrm{t}$-test, $(\mathrm{t}=8.33), 0.001<\mathrm{p}<0.01$.

enhances G2-chromosomal radiosensitivity, which can be observed in the subsequent metaphase as excessive chromosomal fragility. The results obtained using blood samples from different healthy donors are consistent with this hypothesis, as shown in Fig. 1. This outcome is important because excessive fragility, caused by HQ exposure may contribute to chromosomal instability, which is a permissive event in the development of AML $(1,31)$. Concerning the occupational environment, where multiple exposures to harmful agents occur, the increase in radiation-induced chromosomal damage by nonacutely toxic doses of HQ may have important implications for current assessment of safe levels of exposure to HQ. Indeed, the chromosome radiosensitization induced by the combined exposure of HQ and IR is of the same magnitude to that observed by means of the G2-assay in certain radiosensitive syndromes that are also characterised by cancer proneness and increased risk for AML $(18,20,21,24)$. Nevertheless, at present, even though HQ is a widely used chemical in occupational as well as in anthropogenic environment, there is limited data available on the synergistic effect of HQ with other chemical agents (32-35) and so far, no data on the synergistic effect of HQ with ionising radiation have been reported. The results obtained, to our knowledge, represent the first direct evidence that non-acutely toxic doses of HQ affect chromosomal fragility in G2-irradiated human cells. In a recently published manuscript, chromosomal instability was reported to be induced by HQ in a genotype-dependent manner, at doses that were not acutely toxic to stem cells (1). Further to this effect, the results presented here demonstrate that low-dose exposure to HQ that is not acutely toxic may also have important biological and potential clinical consequences when combined with other genotoxic factors. Radiologists and radiologic technologists are among the occupational groups that can be exposed both to HQ and IR and they represent a large segment of the working population exposed to radiation from humanmade sources $(13,36)$. 
The results presented here, may have also important implications for the mechanistic understanding of the leukemogenic potential of HQ, since the excessive fragility and the increased G2-chromosomal radiosensitivity caused by HQ can be linked to cancer proneness. Increased G2-chromosomal radiosensitivity has been examined for more than 20 human inherited cancer-prone conditions (19), using the G2-assay. For instance, the inherited conditions of Ataxia Telangiectasia and Nijmegen breakage syndrome, which exhibit excessive chromosomal fragility either spontaneously or following G2-phase irradiation of PBL, are linked to cancer predisposition and increased risk of AML (18,22,31,37-40). The interesting effect of HQ is, therefore, its potential to increase the G2-chromosomal radiosensitivity of PBL cells in healthy individuals to a level similar to that obtained when PBL from cancer-prone individuals are tested. Indeed, similar yields of chromatid breaks per Gy to the yields obtained in our studies after combined exposure of HQ and IR, were reported when lymphocytes from Ataxia Telangiectasia patients were irradiated with 1 Gy alone and the G2-chromosomal radiosensitivity was estimated using the G2-assay (24). We have reported previously that such an excessive chromosomal fragility in G2-phase depends on the G2-checkpoint response that can be associated with up-regulation of cdk1/cyclin B complex activity and transition of damaged cells from G2- to M-phase (20). Changes in chromatin condensation in the presence of DNA damage during such transition impairs the DNA repair processes resulting in excessive chromosomal fragility $(41,42)$, and recent experimental data demonstrate that checkpoint abrogation in G2-phase compromises repair of chromosomal breaks in Ataxia Telangiectasia cells (24). It has also been reported that a higher level of unrepaired DNAdouble-strand breaks does not provide a universal explanation for the radiation-sensitive Ataxia Telangiectasia phenotype (43).

The mechanism underlying the increased G2-chromosomal radiosensitivity and excessive fragility observed after exposure to HQ could be associated with an effect of HQ on either the initial radiation-induced DNA damage, or on the cellular DNA repair capacity, or also on the cell cycle and feedback control mechanisms during the G2- to M-phase transition $(44,45)$. To elucidate which one of the possible mechanism is involved, four sets of experiments were carried out. The results from the first set of experiments designed to investigate the effect of HQ in the initial radiation-induced chromosomal damage in G0-lymphocytes (Fig. 2), demonstrate that a 24-h preirradiation exposure to HQ $(5 \mu \mathrm{M})$ has no effect in the yield of PCC fragments per cell per Gy when compared to the yield obtained when cells were exposed to IR alone. They suggest, therefore, that the presence of HQ during irradiation has no effect on the initial radiation-induced DNA damage. Consequently, such a mechanism is not directly related to the increased G2-chromosomal radiosensitivity observed in our studies. In the second set of experiments it was tested whether the observed increased G2-chromosomal radiosensitivity after HQ treatment is mediated by an effect of the chemical on the DNA repair processes. Since deficient DNA repair processes should lead to different yields of chromatid breaks after PCC analysis, a higher number of PCC fragment would be expected if HQ had an effect on the DNA repair process. The results shown in Fig. 3, however, demonstrate an equal yield of PCC breaks in the presence or absence of HQ and, therefore, do not support such a possibility. Finally, to test the hypothesis that the observed increase in G2-chromosomal radiosensitivity by HQ is linked to a less efficient G2-checkpoint activation following $\gamma$-irradiation, the MI obtained under the various experimental conditions was estimated and the results are presented in Fig. 4A. The increased MI, when HQ is combined with IR, suggests a positive effect of this chemical on cell cycle progression towards mitosis. Specifically, the results suggest a less efficient G2-checkpoint in the presence of HQ following irradiation. This observation is important since a less efficient G2-M-checkpoint has been recently shown to be associated with an increased cancer risk $(23,25,46)$. A less efficient G2-checkpoint and the transition of damaged cells from G2- to M-phase can be followed by an efficient conversion of DNA damage into chromatid breaks $(41,42)$ suggesting therefore, that this is the most plausible mechanism by which HQ enhances G2-chromosomal radiosensitivity. This hypothesis is further supported by the results obtained when PCC was induced by means of calyculin-A, in 72-h PBL cultures after IR exposure in the presence or absence of HQ. Calyculin-A-induced PCC has been used alone or in combination with other techniques in numerous cytogenetic and biological dosimetry studies $(24,27,47-51)$. In this study, the calyculin-A induced PCC methodology was used as a novel cytokinetic tool not only for MI evaluation but also for the classification of the lymphocytes in the different phases of the cell cycle (G1, S, G2 and M-phase), as shown in Fig. 5. Calyculin-A is a cell permeable inhibitor of protein serine/ threonine phosphatases type 1 and type $2 \mathrm{~A}$, and $\mathrm{PCC}$ is only induced if maturation-promoting factor (MPF) is available, the activity of which depends on the cellular concentration of cyclins, in particular cyclin B (52). Cyclin B concentration oscillates through the cell cycle, it is very low in G1 and increases gradually from $\mathrm{S}$ to $\mathrm{G} 2$. Therefore, calyculin-A induces PCC predominantly in G2-phase followed by S-phase and only slightly in G1-phase (50). A number of late telophase post-mitotic G1 are still visible in the induced PCC but no PCC can be induced in G0 cells by means of calyculin-A alone (53), and new efforts have been recently reported to overcome this problem $(54,55)$. As shown in Fig. 5, in chemically-induced PCCs at G2-phase, the centromeres are not clearly visible, thus making a G2-phase cell easily distinguishable from a metaphase cell (27), enabling therefore the estimation of MI as well as the G2/G2+M ratio. Interestingly, the results obtained from MI analysis using standard cytogenetic technique are equivalent to those obtained from the calyculin-A mediated PCC methodology (Fig. 4). The decreased G2/G2+M ratio after combined exposure to HQ and IR when compared to that obtained after exposure to IR alone (Fig. 6), indicates that HQ partially abrogates the G2-checkpoint and releases cells from the G2-block. Transition of damaged cells from G2- to M-phase results in an increase in G2-chromosomal radiosensitivity and this is consistent with our hypothesis that excessive fragility and increased chromosomal radiosensitivity result from an effect of HQ on cell cycle and feedback control mechanisms during the G2- to M-phase transition.

In summary, the results presented in this manuscript suggest that non-acutely toxic doses of HQ enhance G2- 
chromosomal radiosensitivity in PBL of healthy donors, similar to that observed in certain radiosensitive syndromes that are characterised by cancer proneness and increased risk for AML. Conventional cytogenetics and PCC methodologies were applied to investigate whether HQ affects the initial induction of radiation-induced chromosomal aberration, the repair capacity of chromosomal damage or the G2-checkpoint. The experimental data obtained support the hypothesis that HQ exerts its action by inducing a less efficient G2-M-checkpoint after irradiation, facilitating thus the progression of damaged cells from G2- to M-phase.

\section{Acknowledgments}

This study was supported by the Hellenic Institute for Occupational Health and Safety, and contract no. FIGH-CT2002-00218 awarded by the European Commission.

\section{References}

1. Gowans ID, Lorimore SA, McIlrath JM and Wright EG: Genotype-dependent induction of transmissible chromosomal instability by gamma-radiation and the benzene metabolite hydroquinone. Cancer Res 65: 3527-3530, 2005.

2. Smith MT: Overview of benzene-induced aplastic anaemia. Eur J Haematol 60 (Suppl): 107-110, 1996.

3. Snyder R and Hedli CC: An overview of benzene metabolism. Environ Health Perspect 104 (Suppl 6): 1165-1171, 1996.

4. Whysner J, Reddy MV, Ross PM, Mohan M and Lax EA: Genotoxicity of benzene and its metabolites. Mutat Res 566: 99-130, 2004.

5. Haddad AL, Matos LF, Brunstein F, Ferreira LM, Silva A and Costa D Jr: A clinical, prospective, randomized, double-blind trial comparing skin whitening complex with hydroquinone vs. placebo in the treatment of melasma. Int J Dermatol 42: 153-156, 2003.

6. Nordlund J, Grimes P and Ortonne J: The safety of hydroquinone. J Eur Acad Dermatol Venereol 20: 781-787, 2006.

7. Penner NA and Nesterenko PN: Simultaneous determination of dihydroxybenzenes, aminophenols and phenylenediamines in hair dyes by high-performance liquid chromatography on hypercrosslinked polystyrene. Analyst 125: 1249-1254, 2000.

8. Topping DC, Bernard LG, O'Donoghue JL and English JC: Hydroquinone: acute and subchronic toxicity studies with emphasis on neurobehavioral and nephrotoxic effects. Food Chem Toxicol 45: 70-78, 2007.

9. McDonald TA, Holland NT, Skibola C, Duramad P and Smith MT: Hypothesis: phenol and hydroquinone derived mainly from diet and gastrointestinal flora activity are causal factors in leukemia. Leukemia 15: 10-20, 2001.

10. Joseph P, Klein-Szanto AJ and Jaiswal AK: Hydroquinones cause specific mutations and lead to cellular transformation and in vivo tumorigenesis. Br J Cancer 78: 312-320, 1998.

11. Andreoli C, Rossi S, Leopardi P and Crebelli R: DNA damage by hydroquinone in human white blood cells: analysis by alkaline single-cell gel electrophoresis. Mutat Res 438: 37-45, 1999.

12. Lindsey RH, Bender RP and Osheroff N: Stimulation of topoisomerase II-mediated DNA cleavage by benzene metabolites. Chem Biol Interact 153-154: 197-205, 2005.

13. Makropoulos V and Alexopoulos EC: Case report: hydroquinone and/or glutaraldehyde induced acute myeloid leukaemia? J Occup Med Toxicol 26: 1:19, 2006.

14. Dean BJ, Brooks TM, Hodson-Walker G and Hutson DH: Genetic toxicology testing of 41 industrial chemicals. Mutat Res 153: $57-77,1985$.

15. Zhang L, Yang W, Hubbard AE and Smith MT: Nonrandom aneuploidy of chromosomes 1, 5, 6, 7, 8, 9, 11, 12, and 21 induced by the benzene metabolites hydroquinone and benzenetriol. Environ Mol Mutagen 45: 388-396, 2005.

16. Pasic S, Vujic D, Fiorini M and Notarangelo LD: T-cell lymphoblastic leukemia/lymphoma in Nijmegen breakage syndrome. Haematologica 89(8): ECR27, 2004.
17. Collado R, Hueso J, Cabello AI, et al: New translocations in a case of atypical B-cell chronic lymphocytic leukemia: involvement of ATM, MLL, and TP53 genes. Cancer Genet Cytogenet 169: 176-178, 2006

18. Sanford KK, Parshad R, Gantt R, Tarone RE, Jones GM and Price FM: Factors affecting and significance of G2 chromatin radiosensitivity in predisposition to cancer. Int J Radiat Biol 55: 963-981, 1989.

19. Scott D, Barber JB, Spreadborough AR, Burrill W and Roberts SA: Increased chromosomal radiosensitivity in breast cancer patients: a comparison of two assays. Int J Radiat Biol 75: 1-10, 1999.

20. Terzoudi GI, Jung T, Hain J, et al: Increased G2 chromosomal radiosensitivity in cancer patients: the role of cdk1/cyclin-B activity level in the mechanisms involved. Int $\mathbf{J}$ Radiat Biol 76: 607-615, 2000.

21. Scott D, Spreadborough AR, Jones LA, Roberts SA and Moore CJ: Chromosomal radiosensitivity in G2-phase lymphocytes as an indicator of cancer predisposition. Radiat Res 145: 3-16, 1996.

22. Scott D: Chromosomal radiosensitivity and low penetrance predisposition to cancer. Cytogenet Genome Res 104: 365-370, 2004.

23. Shao L, Hittelman WN, Lin J, Yang H, Ajani JA and Wu X: Deficiency of cell cycle checkpoints and DNA repair system predispose individuals to esophageal cancer. Mutat Res 602: 143-150, 2006.

24. Terzoudi GI, Manola KN, Pantelias GE and Iliakis G: Checkpoint abrogation in $\mathrm{G} 2$ compromises repair of chromosomal breaks in ataxia telangiectasia cells. Cancer Res 65: 11292-11296, 2005.

25. Zheng YL, Loffredo CA, Alberg AJ, et al: Less efficient g2-m checkpoint is associated with an increased risk of lung cancer in African Americans. Cancer Res 65: 9566-9573, 2005.

26. Perry P and Wolff S: New Giemsa method for the differential staining of sister chromatids. Nature 251: 156-158, 1974.

27. Terzoudi GI, Malik SI, Pantelias GE, Margaritis K, Manola K and Makropoulos W: A new cytogenetic approach for the evaluation of mutagenic potential of chemicals that induce cell cycle arrest in the G2 phase. Mutagenesis 18: 539-543, 2003.

28. Carrano AV and Natarajan AT: International Commission for Protection Against Environmental Mutagens and Carcinogens. Considerations for population monitoring using cytogenetic techniques. Mutat Res 204: 379-406, 1988.

29. Pantelias GE and Maillie HD: A simple method for premature chromosome condensation induction in primary human and rodent cells using polyethylene glycol. Somatic Cell Genet 9: 533-547, 1983.

30. Gotoh E, Asakawa Y and Kosaka H: Inhibition of protein serine/threonine phosphatases directly induces premature chromosome condensation in mammalian somatic cells. Biomed Res 16: 63-68, 1995.

31. Jefford CE and Irminger-Finger I: Mechanisms of chromosome instability in cancers. Crit Rev Oncol Hematol 59: 1-14, 2006.

32. Barale R, Marrazzini A, Betti C, Vangelisti V, Loprieno N and Barrai I: Genotoxicity of two metabolites of benzene: phenol and hydroquinone show strong synergistic effects in vivo. Mutat Res 244: 15-20, 1990.

33. Irons RD, Stillman WS, Colagiovanni DB and Henry VA: Synergistic action of the benzene metabolite hydroquinone on myelopoietic stimulating activity of granulocyte/macrophage colony-stimulating factor in vitro. Proc Natl Acad Sci USA 89: 3691-3695, 1992.

34. McCue JM, Lazis S, John Cohen J, Modiano JF and Freed BM: Hydroquinone and catechol interfere with $\mathrm{T}$ cell cycle entry and progression through the G1 phase. Mol Immunol 39: 995-1001, 2003.

35. Stillman WS, Varella-Garcia M and Irons RD: The benzene metabolites hydroquinone and catechol act in synergy to induce dose-dependent hypoploidy and $-5 \mathrm{q} 31$ in a human cell line. Leuk Lymphoma 35: 269-281, 1999.

36. Yoshinaga S, Mabuchi K, Sigurdson AJ, Doody MM and Ron E: Cancer risks among radiologists and radiologic technologists: review of epidemiologic studies. Radiology 233: 313-321, 2004.

37. Bailey SM and Bedford JS: Studies on chromosome aberration induction: what can they tell us about DNA repair? DNA Repair 5: 1171-1181, 2006

38. Fukasawa K: Centrosome amplification, chromosome instability and cancer development. Cancer Lett 230: 6-19, 2005.

39. Raptis S and Bapat B: Genetic instability in human tumors. EXS 96: 303-320, 2006. 
40. Distel LV, Neubauer S, Keller U, Sprung CN, Sauer R and Grabenbauer GG: Individual differences in chromosomal aberrations after in vitro irradiation of cells from healthy individuals, cancer and cancer susceptibility syndrome patients. Radiother Oncol 81: 257-263, 2006.

41. Pantelias GE: Radiation-induced cytogenetic damage in relation to changes in interphase chromosome conformation. Radiat Res 105: 341-350, 1986.

42. Terzoudi GI and Pantelias GE: Conversion of DNA damage into chromosome damage in response to cell cycle regulation of chromatin condensation after irradiation. Mutagenesis 12: 271-276, 1997.

43. Loucas BD and Cornforth MN: Evidence that unrejoined DNA double-strand breaks are not predominantly responsible for chromosomal radiosensitivity of AT fibroblasts. Radiat Res 162: 554-565, 2004.

44. Iliakis G, Wang H, Perrault AR, et al: Mechanisms of DNA double strand break repair and chromosome aberration formation. Cytogenet Genome Res 104: 14-20, 2004.

45. Iliakis G, Wang Y, Guan J and Wang H: DNA damage checkpoint control in cells exposed to ionizing radiation. Oncogene 22: 5834-5847, 2003.

46. Wu X, Roth JA, Zhao H, et al: Cell cycle checkpoints, DNA damage/repair, and lung cancer risk. Cancer Res 65: 349-357, 2005.

47. Bezrookove V, Smits R, Moeslein G, et al: Premature chromosome condensation revisited: a novel chemical approach permits efficient cytogenetic analysis of cancers. Genes Chromosomes Cancer 38: 177-186, 2003.

48. Hatzi VI, Terzoudi GI, Paraskevopoulou C, Makropoulos V, Matthopoulos DP and Pantelias GE: The use of premature chromosome condensation to study in interphase cells the influence of environmental factors on human genetic material. Scientific World J 6: 1174-1190, 2006.
49. Malik SI, Terzoudi GI and Pantelias GE: SCE analysis in G2 lymphocyte prematurely condensed chromosomes after exposure to atrazine: the non-dose-dependent increase in homologous recombinational events does not support its genotoxic mode of action. Cytogenet Genome Res 104: 315-319, 2004.

50. Gotoh E and Durante M: Chromosome condensation outside of mitosis: mechanisms and new tools. J Cell Physiol 209: 297-304, 2006.

51. Gotoh E, Kawata T and Durante M: Chromatid break rejoining and exchange aberration formation following gamma-ray exposure: analysis in G2 human fibroblasts by chemically induced premature chromosome condensation. Int J Radiat Biol 75: 1129-1135, 1999.

52. Doree $\mathrm{M}$ and Galas S: The cyclin-dependent protein kinases and the control of cell division. FASEB J 8: 1114-1121, 1994.

53. Durante M, Furusawa Y and Gotoh E: A simple method for simultaneous interphase-metaphase chromosome analysis in biodosimetry. Int J Radiat Biol 74: 457-462, 1998.

54. Prasanna PG and Blakely WF: Premature chromosome condensation in human resting peripheral blood lymphocytes for chromosome aberration analysis using specific wholechromosome DNA hybridization probes. Methods Mol Biol 291: 49-57, 2005.

55. Prasanna PG, Escalada ND and Blakely WF: Induction of premature chromosome condensation by a phosphatase inhibitor and a protein kinase in unstimulated human peripheral blood lymphocytes: a simple and rapid technique to study chromosome aberrations using specific whole-chromosome DNA hybridization probes for biological dosimetry. Mutat Res 466: 131-141, 2000. 